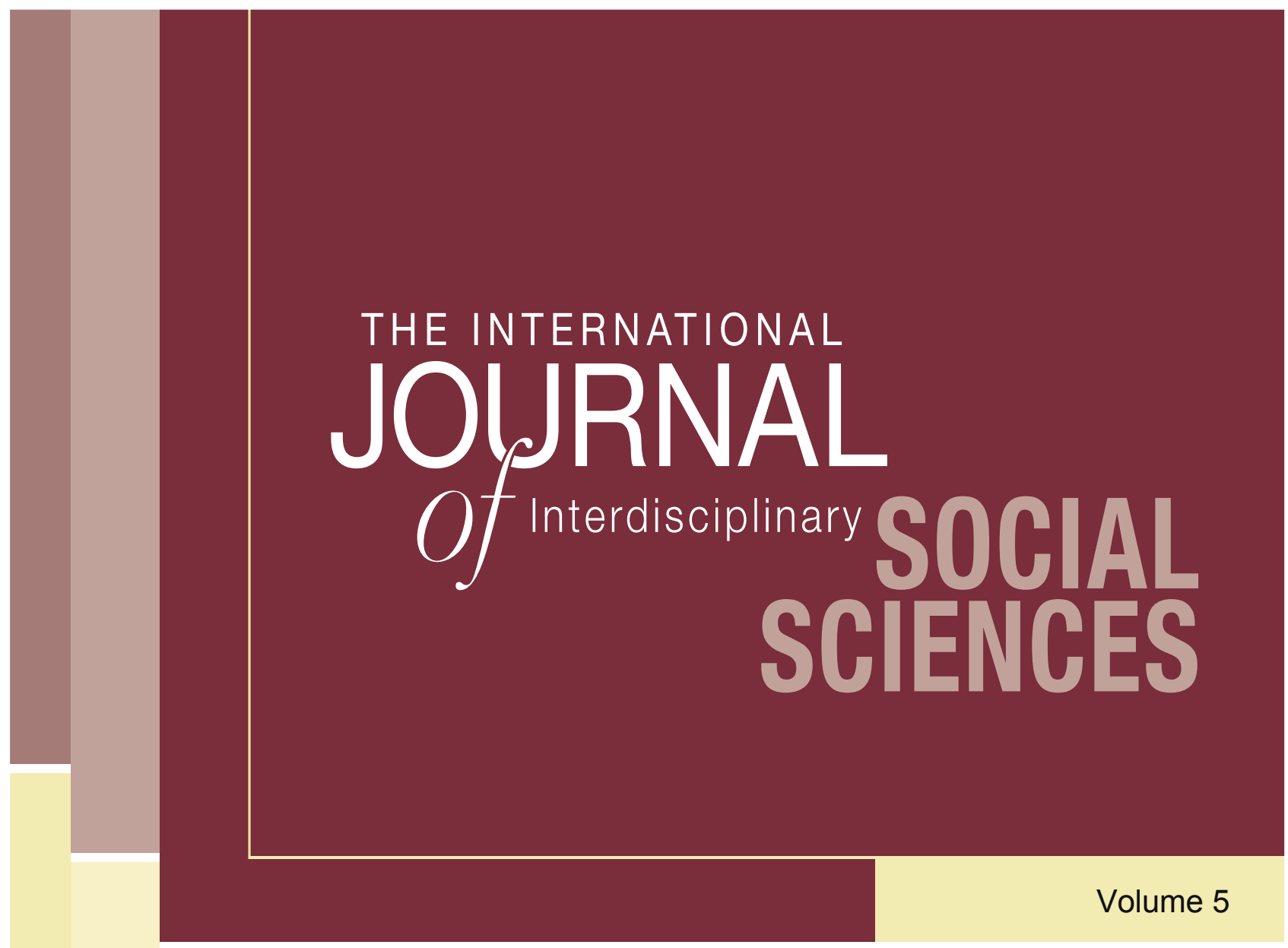

The Impact of Training on Productivity in Canadian Firms: Estimating Distributed Lags from the WES 1999-2005

Amelie Bernier and Jean-Michel Cousineau 
THE INTERNATIONAL JOURNAL OF INTERDISCIPLINARY SOCIAL SCIENCES http://www.SocialSciences-Journal.com

First published in 2010 in Champaign, Illinois, USA by Common Ground Publishing LLC www.CommonGroundPublishing.com.

(C) 2010 (individual papers), the author(s)

(C) 2010 (selection and editorial matter) Common Ground

Authors are responsible for the accuracy of citations, quotations, diagrams, tables and maps.

All rights reserved. Apart from fair use for the purposes of study, research, criticism or review as permitted under the Copyright Act (Australia), no part of this work may be reproduced without written permission from the publisher. For permissions and other inquiries, please contact

<cg-support@commongroundpublishing.com>.

ISSN: $1833-1882$

Publisher Site: http://www.SocialSciences-Journal.com

THE INTERNATIONAL JOURNAL OF INTERDISCIPLINARY SOCIAL SCIENCES is peer-reviewed, supported by rigorous processes of criterion-referenced article ranking and qualitative commentary, ensuring that only intellectual work of the greatest substance and highest significance is published.

Typeset in Common Ground Markup Language using CGCreator multichannel typesetting system

http://www.commongroundpublishing.com/software/ 


\title{
The Impact of Training on Productivity in Canadian Firms: Estimating Distributed Lags from the WES 1999-2005
}

\author{
Amelie Bernier, Université du Québec à Montréal, Quebec, Canada \\ Jean-Michel Cousineau, Université de Montréal, Quebec, Canada
}

\begin{abstract}
This paper estimates the effects of training expenditures on productivity in Canada. The data used are taken from the Statistics Canada Workplace and Employee Survey (WES) for the 1999-2005 period. Among all of the works consulted dealing with the possible impact of training on productivity, more and more treat the longitudinal character of the data, but few consider the delayed effects of the training. Also, the results on this subject differ widely. The longitudinal nature of the WES allows us to address issues of the endogeneity of inputs including human capital and unobserved heterogeneity of establishments as well as omitted variable bias. The impact of training on productivity is measured by estimating a Cobb-Douglas production function within a distributed lag estimation framework. We exploit the advantages of the longitudinal data by estimating a model that considers the impact of training expenditures on productivity, by adding them to the investments in physical capital. The interaction between investments in training and physical capital makes it possible to test the assumption that investments in physical capital and human capital are complementary and mutually supportive. Our results show that investments in training have positive effects on productivity which are spread out over a three-year period.
\end{abstract}

Keywords: Returns on Training, Firm Productivity, Longitudinal Data

\section{Introduction}

$\mathrm{C}$

ANADIAN WORKPLACES PRESENT diversified faces and are experiencing significant change. As a result of factors such as new technologies, globalization, the knowledge economy or even demographic change, Canadian businesses are being transformed through a qualified, adaptable and quality labour force. An examination of the structured training offered by Canadian corporations in our sample from 1999 to 2005 reveals that on average $32.5 \%$ of the firms offered this type of training. Several companies seem to question the necessity of and interest in taking part in ongoing training (Goldenberg, 2006). Is this because they have doubts as to the effect of their training investments on shortterm productivity and their pertinence in the medium term?

This study uses the data of the Workplace and Employee Survey (WES) to estimate the effects of training expenditures on short- and medium-term productivity. Our study is, to the best of our knowledge, the only one that estimates the returns on investments in structured training based on data for Canadian firms and using a recursive model. Our contributions are as follows. First, in order to be a part of the current research trend on the returns on investments of training expenditures, the longitudinal character of the data is used to test and estimate the possible effects beyond the year in which firms make their investments. Then,

The International Journal of Interdisciplinary Social Sciences

Volume 5, 2010, http://www.SocialSciences-Journal.com, ISSN 1833-1882 
in order to adequately measure the return on the training investments made within corporations, it was found necessary to deal with the technical problems pertaining to the idiosyncratic characteristics of the firms and the simultaneity of the training with the dependant variable retained. A time lag model serves to capture the essentials of the problem of endogeneity. Finally, it is still relevant to validate, empirically, the hypothesis of the complementarity of training investments with other types of investments within firms since the results of the longitudinal studies consulted are not always conclusive (Zwick, 2006).

\section{The Problem}

The effects of corporate training were analyzed in an extensive manner in the literature on human capital possibly since its model predicts a direct relationship between productivity and training. It also seems that the debate in the economic literature on labour primarily concerns the fact that companies may or may not benefit from returns on their training investments. In fact, from this point of view, investments in human capital, made through training, are different from investments in physical capital since the employees have the option of leaving the firm, involving them in a cost sharing process. Moreover, tangible and rapid returns can also pose a serious problem in the investment decision for employers, compared to immediate priorities such as investing in new technologies, specifically to ensure their survival or competitiveness on the market. For this reason, it is important for the organization to understand the return on training investments.

First, when a company invests in training, it hopes to obtain monetary gains or improvements in the quality of its human resources. By referring to the theory of human capital and Becker's (1964) model for sharing costs, providing additional training for workers is a means for potentially increasing the company's productivity, through the value of marginal productivity after the training as well as the monetary gains of the employees themselves. Although the theory of human capital has largely demonstrated its empirical application in the explanation of the performance of post-secondary education, we are inclined to believe that it can provide similar and convincing enlightenment with respect to explaining the delayed effects of training, specifically through its translation in terms of the method, of a recursive model applied to the corporate data.

This same theoretical information also suggests that it is important to study the relationship between training and productivity in a sequential manner, by referring to the possible delay between training investments and their returns with companies.

On a theoretical level, this hypothesis makes sense, but on an empirical level, the formal links between training and corporate productivity have not been clearly identified. Thus, the principal stumbling block arises out of the difficulty in obtaining unbiased estimates, since most of the literature surveyed uses transversal research specifications. These studies do not control for the two principal sources of bias in the estimation of training returns, namely: the unobserved heterogeneity among the companies and the potentially endogenous character of training. For example, as Aubert, Crépon and Zamora (2009) point out, the bias of heterogeneity occurs when a company is very productive and invests a great deal in training its workers, although there is no causal link between these two factors. Thus, the training effort could be the result of characteristics that cannot be observed, such as the technology used, human resource management practices, etc. For its part, the bias of simultaneity occurs when the training investments account for variations in productivity but productivity in turn accounts 
for the training efforts, suggesting that the human capital is no longer totally independent of the dependant variable under study. Nevertheless, the empirical literature retained implies that recourse to longitudinal data serves to correct for these sources of technical bias. In fact, a survey of the literature (Colombo and Stanca, 2008; Zwick, 2006) gave us an opportunity to note that the possibly endogenous character of the training is frequently invoked to explain the differences among the estimation results. For our part, we will use the instrumentation of the training investments through its past values which serves to provide unbiased results since we are controlling for the possible simultaneity of training decisions as well as the unobserved heterogeneity among the firms.

This also opens the way for a deeper probe into the possible connections between the various types of investments that serves to verify the hypothesis to the effect that certain production factors are complementary and mutually supportive with respect to improving productivity.

Empirically, there are many issues. In the literature consulted, there does not appear to be any clearly defined relationship between the costs and benefits of training and there seems to be no consensus with respect to returns on this type of investment (Ballot, 2006). In fact, the connections between training and productivity are not as obvious, as we will show. Although an increasing number of studies have attempted to measure the impact of training on certain performance indicators based on data that is representative at the level of the organization (Colombo and Stanca, 2008; Dostie and Pelletier, 2007), the results are not always conclusive. Based on all of the literature examined, there is no unanimity with respect to: 1) the actual measurement of the "training" variable, 2) the type of training to be retained for the purposes of analysis, 3) the results obtained, and 4) the estimation techniques used. In our opinion, there is also no means for making a connection between training investments and the current productivity of corporations. We have to make this connection if we want to understand the impact of training investments for Canadian corporations.

\section{Data and Methodology}

In order to estimate our models concerning the impact of training on the productivity of Canadian firms, we used a sample consisting of 1,621 firms and 11,347 observations. The data used came from the WES employer questionnaire for the 1999-2005 period. All of the estimates made for this study were made using the Stata software (version 10). In summary, our sample included all of the non-profit organizations with at least one employee, reporting positive financial results and for which we have information concerning their training decisions. We will present the results obtained in the next section.

In order to estimate the training return-on-investments (ROI) at the organizational level, we preferred to use a Cobb-Douglas ${ }^{1}$ function presented as a production process $(Q i t)$ serving to relate added value ${ }^{2}$ to training expenses within organizations. Using a Cobb-Douglas function with production $(Q i t)$ as a dependant variable enabled us to study the impact of

\footnotetext{
${ }^{1}$ The principal characteristic of the Cobb-Douglas function resides in the fact that the substitution elasticity is equal to 1 and remains constant along the isoquant curve. A variation in the marginal substitution rate results in a proportional variation in the ratio of the quantities of factors. Referring to the present analysis, this substitution elasticity equal to 1 implies that the factors are both complements and substitutes.

2 The added value is determined by the gross value of production minus the cost of the input (Dostie and Pelletier, 2007).
} 
training on productivity since employment (or the work factor) is an independent variable with constant returns which, in our opinion, allows a solution that is more flexible and less restrictive with respect to estimating the effect of training expenditures on productivity ${ }^{3}$.

As in the case of the work done by Almeida and Carneiro (2006) as well as Barrett and O'Connell (2001), our basic model, characterized by firm $i$ in year $t$ is presented as follows:

$$
\ln Q_{i t}=\ln A_{i t}+\alpha \ln L_{i t}+\beta \ln I_{\text {it }}+\gamma \ln F_{i t}+\delta T_{i t}+\eta X_{i t}+\varepsilon_{i t}
$$

Wherei $=1, \ldots, \mathrm{N} ; \mathrm{t}=1, \ldots, \mathrm{T} ; \alpha ; \beta ; \gamma ; \delta ; \eta$ are parameters to be estimated.

$Q_{\text {it }}$ represents the added value ${ }^{4}$ which is a function of three principal factors $\left(L_{\text {it }} ; I_{\text {it }}\right.$; $\left.H_{\text {it }}\right)$ as well as a scale parameter $\left(A_{\text {it }}\right)$. First, labour $\left(L_{\text {it }}\right)$ is measured by the total number of employees in the firm. Then, we use the investments in physical capital $\left(I_{\text {it }}\right)$ measured by the total amount of equipment expenditures within the organizations (Barett and O'Connell, 2001; Colombo and Stanca, 2008). The investments in human capital $\left(F_{\text {it }}\right)$ are represented by a ratio of expenditures in structured (or formal) training over the total number of employees in the firm ${ }^{5}$. The WES employer questionnaire serves to gather data about the two major training categories: structured training (or formal training) and on-the-job training. Thus, the information available from the WES suggests a differentiation with respect to the predetermined character of the content and the level of the objectives that can be evaluated rather than the division prescribed theoretically which is attached to the general vs specific human capital categories.

Although this is imperfect, a technology variable $\left(T_{\text {it }}\right)$ representing the proportion of employees who use computers as part of their daily work was added to the model. Finally, the equation estimated from the specification (1) also includes a set of control variables represented by a vector $\left(X_{\mathrm{it}}\right)^{6}$.

In order to have an overall view of the possible effects of training on organizational performance, we first estimate the equation (1) using the ordinary least squares (OLS) technique. Moreover, without completely questioning the idea that the differences in the results, in the longitudinal studies, are caused by the fact that training is endogenous to the dependent variable, we checked the predetermined or endogenous character of training in our estimations. In this case, the options considered for dealing with the non-respect of the hypotheses that are subjacent to the OLS include the use of instrumental variables (IV), random effects (RE) or fixed effects (FE), the correction for AR1 auto-correlation, the development of dynamic

\footnotetext{
${ }^{3}$ Productivity refers to measurement of output per work input. In this article, we employ the value added as output. ${ }^{4}$ In order to take into account the effect of inflation on nominal values such as gross operating income, equipment expenses and structured training expenses, we deflated the values by the annual consumer price index for Canada (where 1992=100), as reported by Statistics Canada (CANSIM Table No. 326-0002).

${ }^{5}$ Although training expenditures by employee were seldom used in the previous literature, we believe that they are a reliable and even better indicator of the intensity of the training offered within establishments than frequency or incidence measures, given the reliability of the data provided by Statistics Canada. For example, the response rate of employers in 2005 was $77.7 \%$. Another means for measuring the reliability of the data is to calculate the variation coefficient. If the value obtained is less than $16.5 \%$, the estimation of the variable $F$ it will be considered reliable. In our case, the variation coefficient is $3.57 \%$ which indicates that the data used is homogenous.

${ }^{6}$ The controls for each dependent variable included the presence of union $(=1$ for unionized environment and equals 0 otherwise), the establishments with an HR Unit ( $=1$ if workplace has a human resource unit and equals 0 otherwise), the level of competition ( $=1$ if no competitors and 0 otherwise), the percent of firm assets that are foreign held, the proportion of women, the proportion of employees that are part-time and the voluntary turnover rate (proportion of total employment that quit on total number of employee). We also control for industry (14), occupation and time.
} 
models using the generalized method of moments and the recourse to the analysis of longitudinal data.

As we have already pointed out, a delay of at least one year is necessary since a problem of endogeneity would occur if the decisions pertaining to the training investments and productivity of organizations were made at the same time. Thus, since we suppose that the decision to invest in training and its return on investment in terms of increased productivity may include a significant delay, we therefore estimate a model in which the length of the delay is specified $(\mathrm{t}=4)$. The variable of the investment in physical capital $\left(I_{\mathrm{it}}\right)$ will also be deferred in time. In order to apply these delays, we should re-write the equation (1) as follows:

$\ln Q_{u}=\ln A+\alpha \ln L_{u}+\sum_{j=1}^{4} \beta j \ln I_{u-j}+\sum_{j=1}^{4} \gamma_{j} \ln F_{u-j}+\delta T_{u t}+\eta X_{u t}+\varepsilon_{u t}$

Where $\mathrm{j}$ varies from 1 to 4 years; $b_{1}=\sum_{j=1}^{4} \beta_{j} ; b_{2}=\sum_{j=1}^{4} \gamma_{j}$

Moreover, in order to validate the hypothesis concerning the complementarity of the effects of investments in training $\left(F_{\text {it }}\right)$ and investments in physical capital $\left(I_{\text {it }}\right)$ on productivity, we include a multiplier represented by a symbol (*) between $F_{\text {it }}$ and $I_{\text {it }}$ that can be seen in equation (3):

$$
\ln Q_{i t}=\ln A_{i t}+\alpha \ln L_{i t}+\sum_{j=1}^{4} \beta_{j} \ln I_{i t-j}+\sum_{j=1}^{4} \phi_{j} \ln I_{i t-j} * \ln F_{i t-j}+\delta T_{i t}+\eta X_{i t}+\varepsilon_{i t}
$$

Where $\mathrm{j}$ varies from 1 to 4 years; $b_{1}=\sum_{j=1}^{4} \beta_{j} ; b_{2}=\sum_{j=1}^{4} \gamma_{j}$

The following section presents the results obtained for all of our estimates.

\section{The Results}

\section{The Endogenous Character of Training}

Performing the Nakamura-Nakamura endogeneity test (Nakamura and Nakamura, 1998) indicates that the results are at the limit of the null hypothesis acceptance threshold (absence of endogeneity). A second means for testing for the presence of endogeneity is the Hausman test. Once again, the results obtained suggest that the null hypothesis of the explanatory variables should be rejected, which leaves the possibility that the training variable is endogenous to productivity ${ }^{7}$. To correct this potential bias, training should be estimated over a long period of time, so as to document all of the possible returns, making it interesting to use a recursive model to measure the impacts of training investments with more than one year of delay. For example, Model 2 (Table 4.1-1) indicates that the exogenous portion of the training variable exercises a positive and significant effect on productivity. Thus, it can be seen that a $10 \%$ increase in expenditures for structured training per employee results in a $1.7 \%$ increase in the firm company's productivity for the following year.

\footnotetext{
${ }^{7}$ The results of these estimates are available upon request.
} 
Table 4.1-1: Results of Estimates of the Impact of Training Expenditures on the Productivity of Canadian Corporations from 1999 to 2005

\begin{tabular}{|c|c|c|c|c|c|}
\hline \multirow{2}{*}{$\begin{array}{l}\text { Dependent Variable: } \\
\text { In Production (added value) } \\
\text { Explanatory variables }\end{array}$} & Model 1 & Model 2 & Model 3 & Model 4 & Model 5 \\
\hline & OLS & IV & $\mathbf{R E}$ & $\mathbf{F E}$ & AR1, RE \\
\hline Ln (total number of employees) & $\begin{array}{c}0.8306^{* * *} \\
(0.0253)\end{array}$ & $\begin{array}{c}1.0081^{* * *} \\
(0.0183)\end{array}$ & $\begin{array}{c}0.8069^{* * *} \\
(0.0295)\end{array}$ & $\begin{array}{c}0.5611^{* * *} \\
(0.0592)\end{array}$ & $\begin{array}{c}0.8096^{* * *} \\
(0.0289)\end{array}$ \\
\hline $\begin{array}{l}\text { Proportion of employees using a } \\
\text { computer } \\
\text { (as a percentage) }\end{array}$ & $\begin{array}{c}0.0040 * * * \\
(0.0007)\end{array}$ & $\begin{array}{c}0.0025^{* * *} \\
(0.0004)\end{array}$ & $\begin{array}{c}0.0025^{* * *} \\
(0.0006)\end{array}$ & $\begin{array}{l}0.0012^{*} \\
(0.0006)\end{array}$ & $\begin{array}{c}0.0026^{* * *} \\
(0.0006)\end{array}$ \\
\hline ln (investment in physical capital) & & $\begin{array}{c}0.0346^{* * *} \\
(0.0117)\end{array}$ & & & \\
\hline $\begin{array}{l}\text { ln (structured training expenses/total } \\
\text { number of employees) } t-1\end{array}$ & \begin{tabular}{|c|}
-0.0119 \\
$(0.0253)$ \\
\end{tabular} & $\begin{array}{c}0.1656^{* * *} \\
(0.0203) \\
\end{array}$ & \begin{tabular}{|l|}
-0.0006 \\
$(0.0136)$
\end{tabular} & $\begin{array}{l}-0.0081 \\
(0.0157)\end{array}$ & $\begin{array}{c}0.0002 \\
(0.0138)\end{array}$ \\
\hline $\begin{array}{l}\ln \text { (structured training expenses/total } \\
\text { number of employees) } \mathrm{t}_{\mathrm{t}} 2\end{array}$ & $\begin{array}{c}0.0047 \\
(0.0283)\end{array}$ & & $\begin{array}{c}0.0175 \\
(0.0131)\end{array}$ & $\begin{array}{c}0.0029 \\
(0.0151)\end{array}$ & $\begin{array}{c}0.0178 \\
(0.0132)\end{array}$ \\
\hline $\begin{array}{l}\ln \text { (structured training expenses/total } \\
\text { number of employees) } \mathrm{t}-3\end{array}$ & $\begin{array}{c}0.0340 \\
(0.0270)\end{array}$ & & $\begin{array}{c}0.0374 * * * \\
(0.0124)\end{array}$ & $\begin{array}{c}0.0206 \\
(0.0141)\end{array}$ & $\begin{array}{c}0.0380^{* * *} \\
(0.0126)\end{array}$ \\
\hline $\begin{array}{l}\ln \text { (structured training expenses/total } \\
\text { number of employees) } \mathrm{t}-4\end{array}$ & $\begin{array}{c}0.0341 \\
(0.0238)\end{array}$ & & $\begin{array}{c}0.0094 \\
(0.0124)\end{array}$ & $\begin{array}{l}-0.0086 \\
(0.0137)\end{array}$ & $\begin{array}{c}0.0107 \\
(0.0126)\end{array}$ \\
\hline $\ln$ (investment in physical capital) $_{\mathrm{t}-1}$ & $\begin{array}{c}0.0177 \\
(0.0304)\end{array}$ & & $\begin{array}{c}0.0659 * * * \\
(0.0165)\end{array}$ & $\begin{array}{c}0.0282 \\
(0.0205)\end{array}$ & $\begin{array}{c}0.0683^{* * *} \\
(0.0167)\end{array}$ \\
\hline${ }_{2}$ ln (investment in physical capital) $t$ - & $\begin{array}{l}0.0538^{*} \\
(0.0330)\end{array}$ & & $\begin{array}{c}0.0510 * * * \\
(0.0159)\end{array}$ & $\begin{array}{c}0.0051 \\
(0.0190)\end{array}$ & $\begin{array}{c}0.0508^{* * *} \\
(0.0161)\end{array}$ \\
\hline $\begin{array}{l}\ln (\text { investment in physical capital) } \mathrm{t} \text { - } \\
3\end{array}$ & $\begin{array}{c}0.0397 \\
(0.0286)\end{array}$ & & $\begin{array}{c}0.0338 * * * \\
(0.0128)\end{array}$ & $\begin{array}{l}-0.0049 \\
(0.0146)\end{array}$ & $\begin{array}{c}0.0338^{* * *} \\
(0.0130)\end{array}$ \\
\hline $\ln$ (investment in physical capital) $t$ - & $\begin{array}{c}0.0542 * * \\
(0.0218)\end{array}$ & & $\begin{array}{c}0.0260 * * \\
(0.0109)\end{array}$ & $\begin{array}{l}-0.0007 \\
(0.0116)\end{array}$ & $\begin{array}{c}0.0279 * * * \\
(0.0111)\end{array}$ \\
\hline Total number of observations $(\mathrm{N})$ & 1555 & 4477 & 1555 & 1555 & 1555 \\
\hline Total number of firms (n) & & 1080 & 620 & 620 & 620 \\
\hline R square of model & 0.7814 & 0.7649 & 0.7728 & 0.6839 & 0.7738 \\
\hline \multicolumn{6}{|c|}{$\begin{array}{l}\text { Notes: } 1 \text {. Robust standard deviations in parentheses. }{ }^{* *} \text { significant to } 1 \% * * \text { significant } \\
\text { to } 5 \% * \text { significant to } 10 \% \\
\text { 2. One constant, dichotomous variables for the industry (14), time, as well as control vari- } \\
\text { ables are also included in the models. The full results are available upon request. }\end{array}$} \\
\hline
\end{tabular}

\section{Delayed Effects of Training on Productivity}

With respect to the time lag models, the structure of the delays is time t-1 to t-4. Time " $\mathrm{t}$ " for the current year is not retained so as to avoid potential problems with simultaneity. When 
the delayed effects of training are examined, the results also suggest that shorter delays have a low impact, confirming the hypothesis of the theory of human capital, and then increase over time. In Models 1, 3, 4 and 5 (Table 4.1-1), the coefficient estimated at t-3 suggests that there is an adjustment period between the training expenses and the profitability of the investment. This explanation, which is associated with returns in training investments, holds for all of the estimated recursive models. Also, the results presented in Models 3 to 5 show that the results for the training variable present a profitability structure that is different than that for investments in physical capital. The structure of the delays ( $t-1$ to $t-4)$ to account for the impact of training on the productivity of Canadian firms has an inverted $U$ shape: initially it shows a period of growth, reaches a peak and then declines. The addition of control variables does not change this observation at all. The usual concept that applies to physical investments does not necessarily apply to investments in human capital.

\section{The Complementarity of Production Factors}

The results of the estimates that take into account the interaction between investments in capital and training investments are reported in Table 4.3-1. The interaction between the investments in physical capital and training served to verify the hypothesis that investments in physical capital and human capital are complementary and mutually supportive. The interaction variable $\ln F_{\mathrm{it}}{ }^{*} \ln I$ it has a positive and significant coefficient for Models 6 and 7, indicating the complementarity between $F_{\text {it }}$ and $I_{\text {it }}$ in terms of firm productivity. For example, the interpretation of the global effect of $I_{\text {it }}$ and the interaction between $F$ it and $I$ it in Model 6 signifies that a 10\% increase in investments enriched by expenditures in structured training per employee will result in an average increase of $0.6 \%(0.0598+0.0013)$ in corporate productivity the following year, compared to a company that has not integrated practices complementary to training, such as investments in physical capital.

Table 4.3-1: Results of the Estimates of the Joint Effect of Training Expenditures and Investments in Physical Capital on the Productivity of Canadian Corporations, from 1999 to 2005

\begin{tabular}{|c|c|c|}
\hline \multirow{2}{*}{$\begin{array}{l}\text { Dependent Variable : } \\
\text { In Production ( added value ) } \\
\text { Explanatory Variables }\end{array}$} & Model 6 & Model 7 \\
\hline & $\begin{array}{c}\text { AR1, RE } \\
(t-1)\end{array}$ & $\begin{array}{c}\text { AR1, RE } \\
(t-4)\end{array}$ \\
\hline Ln (total number of employees) & $\begin{array}{c}0.9080^{* * *} \\
(0.0167)\end{array}$ & $\begin{array}{c}0.8091 * * * \\
(0.0289)\end{array}$ \\
\hline $\begin{array}{l}\text { Proportion of employees using a computer } \\
\text { (as a percentage) }\end{array}$ & $\begin{array}{c}0.0026^{* * *} \\
(0.0004)\end{array}$ & $\begin{array}{c}0.0026^{* * *} \\
(0.0006)\end{array}$ \\
\hline ln (investment in physical capital) $t-1$ & $\begin{array}{c}0.0598^{* * *} \\
(0.0090)\end{array}$ & $\begin{array}{c}0.0691 * * * \\
(0.0173)\end{array}$ \\
\hline
\end{tabular}


THE INTERNATIONAL JOURNAL OF INTERDISCIPLINARY SOCIAL SCIENCES

\begin{tabular}{|c|c|c|}
\hline $\ln$ (investment in physical capital) $\mathrm{t}_{-2}$ & & $\begin{array}{c}0.0441 * * * \\
(0.0167)\end{array}$ \\
\hline $\ln \left(\right.$ investment in physical capital) $t_{t-3}$ & & $\begin{array}{c}0.0205 \\
(0.0136)\end{array}$ \\
\hline $\ln$ (investment in physical capital) $\mathrm{t}-4$ & & $\begin{array}{c}0.0244 * * \\
(0.0120)\end{array}$ \\
\hline ln Training * $\ln$ Investments in physical capital $t-1$ & $\begin{array}{c}0.0013^{* *} \\
(0.0006)\end{array}$ & $\begin{array}{c}-0.0000 \\
(0.0008)\end{array}$ \\
\hline $\ln$ Training * $\ln$ Investments in physical capital ${ }_{\mathrm{t}-2}$ & & $\begin{array}{c}0.0012 \\
(0.0008)\end{array}$ \\
\hline ln Training $*$ ln Investments in physical capital ${ }_{\mathrm{t}-3}$ & & $\begin{array}{c}0.0022 * * * \\
(0.0008)\end{array}$ \\
\hline ln Training * $\ln$ Investments in physical capital $t-4$ & & $\begin{array}{c}0.0006 \\
(0.0008)\end{array}$ \\
\hline Total number of observations $(\mathrm{N})$ & 4487 & 1555 \\
\hline Total number of firms (n) & 1088 & 620 \\
\hline R square of the model & 0.7738 & 0.7736 \\
\hline \multicolumn{3}{|c|}{$\begin{array}{l}\text { Notes: } \\
\text { 1. Robust standard deviations in parentheses. } * * * \text { significant to } 1 \% * * \text { significant to } 5 \% * \\
\text { significant to } 10 \% \\
\text { 2. One constant, dichotomous variables for the industry (14), time, as well as control vari } \\
\text { ables are also included in the models. The full results are available upon request. }\end{array}$} \\
\hline
\end{tabular}

\section{Conclusion}

Our results certainly justify the use of longitudinal data in the study of the returns on training investments. We take advantage of the longitudinal data by estimating a model that considers the impact on productivity of both of training expenditures and the investments in physical capital. Because of the interaction between investments in training and physical capital, the assumption that, investments in physical capital and human capital are complementary and support themselves mutually can be tested. Our results show that investments in training have positive effects on productivity which are spread out over a tree years period.

One of the major challenges of our research was associated with the choice of the estimator to be used in order to obtain unbiased results. Thus, there are several advantages to using a longitudinal database, as in the case of the Statistics Canada Workplace and Employee $S$ urvey. The fact of using a model with longitudinal data increases the ability to conduct dynamic research. As a result, the study of training within corporations can be documented better, particularly in terms of causal effects. Moreover, it is also possible to detect effects that cannot normally be perceived with the use of transversal data, including ambiguous short-term effects which are quite significant on a medium-term basis. Investments in 
structured training are, therefore, profitable for Canadian companies since they keep a portion of the gains, particularly in terms of increased productivity.

Despite the empirical support for medium-term returns on investments in training for Canadian firms, the question can be raised as to why they do not provide more training since the returns on training investments are substantial? One of the reasons for this reticence is the fear of seeing employees leave for better opportunities elsewhere. In complementary studies, we will attempt to provide additional clarification about the issue of the impact of investments in structured training per employee on the various aspects of the turnover rate within Canadian firms.

\section{References}

Almeida, R. and P. Carneiro (2006). "The return to the Firm Investment in Human Capital”. Discussion Paper Series, no. 1937, Institute for the Study of Labor (IZA).

Aubert, P., Crépon, B. and Zamora, P. (2009). "Le rendement apparent de la formation continue dans les entreprises : effets sur la productivité et les salaries”. Économie et Prévision, Vol.1 (187), $25-46$.

Ballot, G., Fakhfakh, F. and Taymaz, E. (2006). "Who Benefits from Training and R\&D, the Firm or the Workers?”. British Journal of Industrial Relations, Vol. 44 (3), 473-495.

Barney, J. (1991). Firm Resources and Sustained Competitive Advantage. Journal of Management, Vol. 17 (1), 99-120.

Bassi, L., Harrison, P., Ludwig, J. and McMurrer, D. (2001). "Human Capital Investments and Firm Performance". Working Paper, Human Capital Dynamics: Washington.

Becker, G. (1964). Human capital: A theoretical and empirical analysis, with special reference to education, New York: National Bureau of Economic Research.

Colombo, E. and L. Stanca (2008). "The impact of Training on Productivity: Evidence from a Large Panel of Firms". Working Papers 134, University of Milano-Bicocca, Department of Economics.

Dostie, B. and Pelletier, M.-P. (2007). "Les rendements de la formation en enterprise". Canadian Public Policy/Analyse des Politiques. Vol. XXXIII (1), 21-40.

Goldenberg, M. (2006). Investissements des employeurs dans l'apprentissage en milieu de travail au Canada. Research document prepared by Canadian Policy Research networks for the Canadian Council on Learning.

Nakamura, A., and Nakamura, M. (1998). "Model specification and endogeneity". Journal of Econometrics, Vol. 83 (1-2), 213-237.

Zwick, T. (2006). "The impact of training intensity on establishment productivity". Industrial Relations, Vol. 45 (1), 26-46.

\section{About the Authors}

Amelie Bernier

The results presented in this article are the fruit of chapter 1 of my Ph.D. dissertation submitted to the Université de Montréal in June 2010.

Professor Jean-Michel Cousineau

Université de Montréal, Canada 



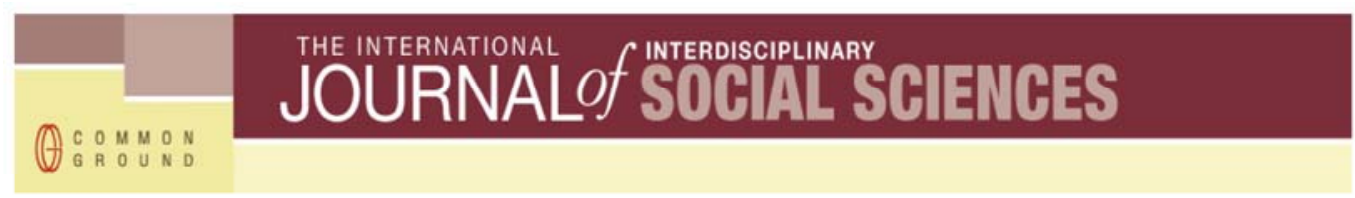

\section{EDITORS}

Mary Kalantzis, University of Illinois, Urbana-Champaign, USA.

Bill Cope, University of Illinois, Urbana-Champaign, USA.

\section{EDITORIAL ADVISORY BOARD}

Patrick Baert, Cambridge University, Cambridge, UK.

Norma Burgess, Syracuse University, Syracuse, USA.

Bill Cope, University of Illinois, Urbana-Champaign, USA.

Peter Harvey, University of Adelaide, Adelaide, Australia.

Vangelis Intzidis, University of the Aegean, Rhodes, Greece.

Paul James, RMIT University, Melbourne, Australia.

Mary Kalantzis, University of Illinois, Urbana-Champaign, USA.

Gerassimos Kouzelis, University of Athens, Athens, Greece.

Massimo Leone, University of Turin, Turin, Italy.

Alexandros-Andreas Kyrtsis, University of Athens, Athens, Greece.

José Luis Ortega Martín, Universidad de Granada, Granada, Spain.

Bertha Ochieng, University of Bradford, Bradford, UK.

Francisco Fernandez Palomares, Universidad de Granada, Granada, Spain.

Miguel A. Pereyra, Universidad de Granada, Granada, Spain.

Constantine D. Skordoulis, University of Athens, Athens, Greece.

Chad Turnbull, ESADE Business School, Barcelona, Spain.

Chryssi Vitsilakis-Soroniatis, University of the Aegean, Rhodes, Greece.

Please visit the Journal website at http://www.SocialSciences-Journal.com for further information about the Journal or to subscribe. 


\section{THE UNIVERSITY PRESS JOURNALS}

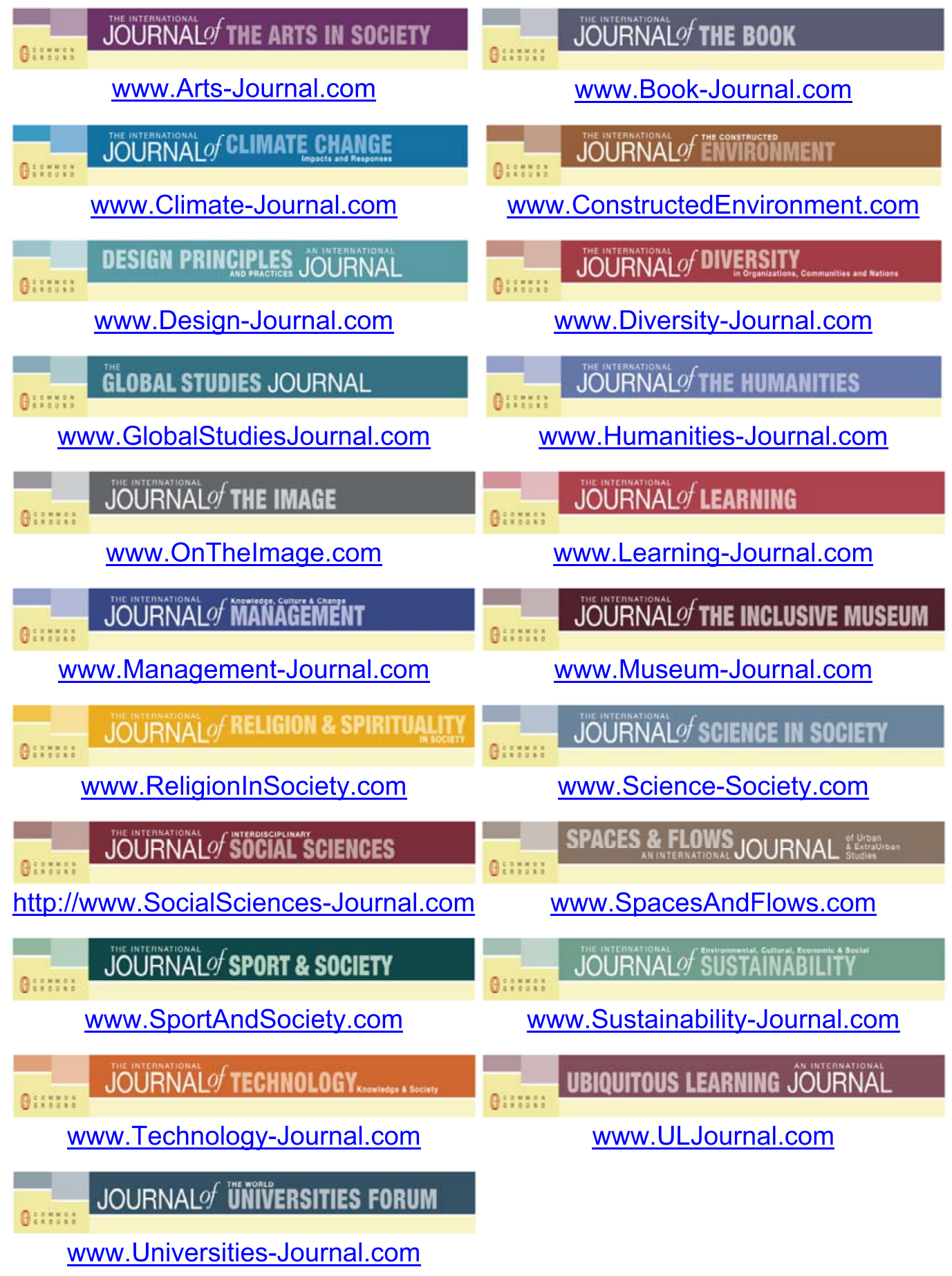

FOR SUBSCRIPTION INFORMATION, PLEASE CONTACT subscriptions@commongroundpublishing.com 